\title{
THE EFFICIENCY OF THE ASSAY FOR HAEMOPOIETIC COLONY FORMING CELLS
}

\author{
S. K. Lahiri, H. J. Keizer and L. M. van Putten \\ Department of Radiation Biology, Rotterdam Medical Faculty, \\ and Radiobiological Institute TNO, Rijswijk, The Netherlands
}

(Received 12 December 1969 ; revision received 16 February 1970)

\begin{abstract}
The quantitative efficiency of the spleen colony assay in mice is discussed in the light of recent findings on the kinetics of colony forming cells. Arguments are presented showing that the $f$ factor, the $2 \mathrm{hr}$ CFU recovery fraction in the spleen, markedly over-estimates the assay efficiency which is the ratio of the numbers of colony forming units and colony forming cells.
\end{abstract}

\section{INTRODUCTION}

In 1961 Till \& McCulloch described a spleen colony technique for the assay of bone marrow stem cells in mice and they introduced the term 'colony forming units' (CFU) for the cells in a bone marrow or spleen cell population which upon injection into an irradiated recipient gave rise to colonies on the surface of the spleen.

Siminovitch, McCulloch \& Till (1963) tried to determine the efficacy of the transplantation technique. Only a fraction $(f)$ of the injected colony forming cells lodges in the spleen and forms colonies. A measurement of $f$ is obtained by injecting animals with a marrow cell suspension containing a known number of CFU and determining the number of CFU that may be recovered from the recipient's spleen $2-3 \mathrm{hr}$ later, when the recovery curve has a plateau. The assumption that $f$ is a measure of the efficiency of the assay, implies that each of the colony forming cells (CFC) present in the spleen at $2 \mathrm{hr}$ after injection will form a colony there.

Since the number of CFC in the spleen at $2 \mathrm{hr}=$ the number of colonies in the spleen at 9 days $=$ the number of CFU injected,

$$
\begin{aligned}
f & =\frac{\text { CFU in spleen at } 2 \mathrm{hr}}{\mathrm{CFU} \text { injected }}=\frac{\mathrm{CFU} \text { in spleen at } 2 \mathrm{hr}}{\text { Colonies in spleen at } 9 \text { days }} \\
& =\frac{\mathrm{CFU} \text { in spleen at } 2 \mathrm{hr}}{\mathrm{CFC} \text { in spleen at } 2 \mathrm{hr}}
\end{aligned}
$$

Correspondence: Dr S. K. Lahiri, Radiobiological Institute TNO, 151 Lange Kleiweg, Rijswijk Z. H., The Netherlands. 
The mean of $f$ was found to be $0 \cdot 17$ (Siminovitch et al., 1963) but it was concluded that the use of this value for $f$ provides a minimum estimate of the number of colony forming cells in a suspension because cells lost or damaged in the preparation of the suspension are not taken into account.

We have reasons to believe that the true number of CFC may be under-estimated by a wider margin than on this account alone. In the course of a series of studies on the growth kinetics of CFU after injection into irradiated recipients it was found that the number of CFU that may be recovered from a normal recipient's spleen $24 \mathrm{hr}$ after injection is always lower than at $2 \mathrm{hr}$ after injection (Lahiri \& van Putten, 1969a). Similar findings have been reported by McCulloch \& Till (1964), Schooley (1966), Pozzi \& Silini (1968), Kubanek et al. (1969) and Kretchmar \& Conover (1969a). If it can be shown that this corresponds to a loss of $\mathrm{CFC}$, it is evident that the $2 \mathrm{hr} f$ factor can no longer be regarded as a true measure of assay efficiency, since not all the CFC present in the spleen $2 \mathrm{hr}$ after injection can form colonies.

\section{MATERIALS AND METHODS}

Experimental mice and CFU assay techniques have been described earlier (Lahiri \& van Putten, 1969a). Briefly, whole spleens or all the bone marrow cells contained in a number of femurs from inbred female Swiss mice were collected in sterile Tyrode's solution and suitable aliquots were injected into the tail veins of isogenic recipients irradiated with 700 rads of $\mathrm{X}$-rays. Later, the radiation dose was increased to 750 rads. This did not change the efficacy of the in vivo assay system, but suppressed background colonies better. Nine days after injection, colonies larger than $0.25 \mathrm{~mm}$ diameter were counted after fixation of spleens in Tellyesniczky's solution.

The standard procedure for studying the 'dip' in the CFU recovery curve was as follows: Various types of donor cell suspensions were injected into heavily irradiated recipients. At various intervals after injection, including 2 and $24 \mathrm{hr}$, five or more of these recipients were killed and the number of CFU in their spleens was determined by assay in secondary recipients. This permitted the determination of the decrease of the number of CFU that could be recovered from the recipient's spleen over the time interval between 2 and $24 \mathrm{hr}$ after injection, and it was observed that this decrease varied with the source of the CFU and with the preparation of the recipient. Donor cell suspensions were obtained from: normal femoral bone marrow, from spleens of sublethally irradiated donors 13 days after 450 rad when the CFU content in the spleen was growing exponentially and from spleens of lethally irradiated donors injected with bone marrow (chimaera spleen) at different time intervals. The variable in the recipients was the time interval between irradiation and bone marrow injection; the normal standard procedure observed an interval of $1-3 \mathrm{hr}$ and this was changed to 3 days in studies on modification of the dip.

\section{RESULTS AND DISCUSSION}

The standard femur CFU growth curve in recipient spleens described earlier (Lahiri \& van Putten, 1969a), shows a decrease between 2 and $24 \mathrm{hr}$ after injection by a factor of approximately 3 (in female Swiss mice from $25 \%$ to $9 \%$ and in male C $57 \mathrm{BL}$ mice from $20 \%$ 


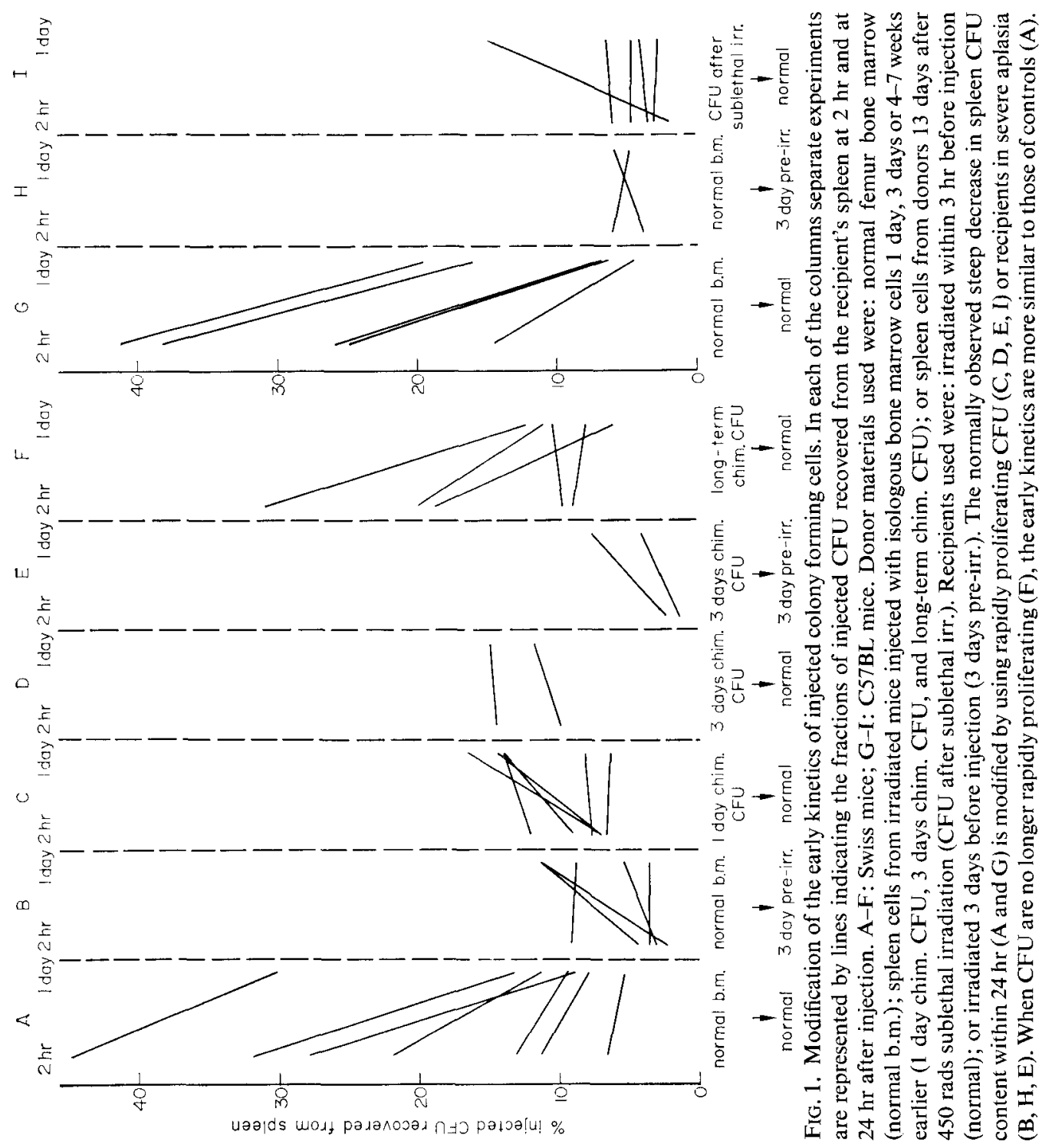


to $6 \%$ of the number of CFU injected (Lahiri \& van Putten, 1969b). However, this dip may be abolished by various types of modification either in the donor or in the recipient of the cell suspension (Fig. 1). If the CFU are growing rapidly in the donor, the dip in the recipient is abolished or decreased. This finding is not easily explained assuming that the dip is caused by migration of CFU (Kretchmar \& Conover, 1969b, c) or by artifacts in the technique.

The dip is also absent when the interval between irradiation and injection of recipients is 3 days. It seems likely that the dip is associated with a lack of self replication of CFU in a recently irradiated host and the most likely explanation is that the dip is a consequence of differentiation of CFU. Whatever the reason for the dip may be, it must correspond to a real decrease in the number of colony forming cells in the spleen, unless there is a loss in their retransplantation efficiency within the first $24 \mathrm{hr}$ after injection.

To study the role of variations in transplantability in causing the dip, we determined the kinetics of CFU obtained from spleens of mice that had been irradiated and injected with bone marrow cells $2 \mathrm{hr}$ and 1 day earlier ( $2 \mathrm{hr}$ and 1 day chimaeras). Suspensions of these chimaera spleens were injected into secondary recipients, and the CFU content of the spleens of the secondary recipients was determined at $2 \mathrm{hr}$ and $24 \mathrm{hr}$ by the standard spleen colony assay in tertiary recipients (Table 1).

TABLE 1. Recovery of injected chimaera spleen CFU from the spleens of recipients at different times

\begin{tabular}{lcc}
\hline & 2 hr chimaera CFU & 1 day chimaera CFU \\
\hline 2 hr recovery & $10 \cdot 1 \pm 1.3 \%$ & $6.9 \pm 0.3 \%$ \\
1 day recovery & $5 \cdot 8 \pm 1.2 \%$ & $11 \cdot 3 \pm 2.5 \%$ \\
\hline
\end{tabular}

Mean and SE of four experiments.

Though the $2 \mathrm{hr} f$ factors of CFU derived from spleens of chimaeras $2 \mathrm{hr}$ and 1 day post injection were indeed different, this difference was small and it was reversed $22 \mathrm{hr}$ later. Also, the 1 day recovery fraction of $2 \mathrm{hr}$ chimaera CFU, and the $2 \mathrm{hr}$ recovery fraction of 1 day chimaera CFU, are similar. These donor CFU have spent $26 \mathrm{hr}$ in irradiated mice in both cases, and their final retransplantability seems similar.

Just as in the case of the endogenous system studied by Fred \& Smith (1968), our data show that a variation in transplantability can account for only a small part of the dip in the recovery of transplanted CFU.

Another argument against variation in retransplantability as the sole cause of the dip can be found by a comparison between endogenous and exogenous colony formation. A decrease of the surviving CFU number in the femurs has been described by Porteous \& Lajtha (1966), Hanks \& Ainsworth (1967) and Smith, Wilson \& Fred (1968). A similar decrease in CFU content may also be observed in the spleens of sublethally irradiated mice and the time course of this decrease parallels the decrease in spleen CFU content in lethally irradiated mice, injected with bone marrow cells (Fig. 2). In the sublethally irradiated mice, for every endogenous spleen colony found at 9 days there were about 2.5 CFU in the spleen immediately after irradiation (Fig. 2). Since there must have been more CFC than CFU, it is evident that not every CFC present in the spleen at this time, later produced a colony. It is clear that in this case the decrease in CFU cannot be caused by a variation in transplantability. 
By analogy we may conclude with some confidence that a similar phenomenon occurs in the exogenous system. Not only the number of CFU, but also the number of CFC in the spleen of a bone marrow recipient shows a real decrease between 2 and $24 \mathrm{hr}$ after injection, and not all CFC present at $2 \mathrm{hr}$ can form colonies.

This implies that the efficiency factor for CFU transplantation is not equal to the $2 \mathrm{hr}$ recovery fraction.

The number of CFU recoverable from a spleen at the plateau of the dip in the recovery curve will be the consequence of an equilibrium between a slowly protracted decrease in

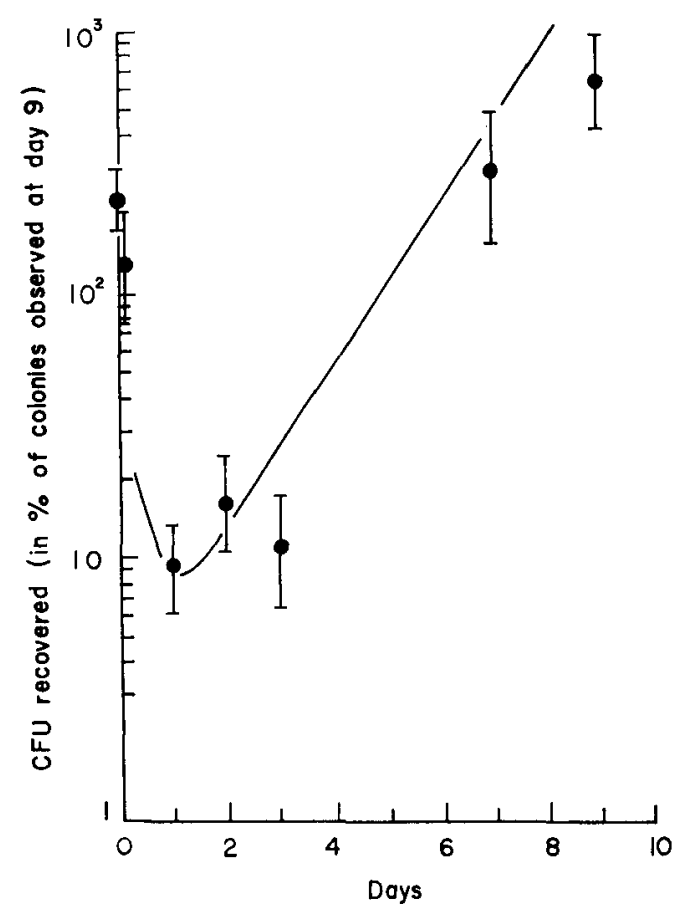

Fig. 2. Comparison of the growth of endogenous CFU in the spleens of sublethally irradiated mice with the growth of injected bone marrow CFU in the spleens of lethally irradiated recipients. The growth of transplanted CFU is represented by the curve (Lahiri \& van Putten, 1969a), the endogenous CFU content is represented by the dots (mean and SE of three or four separate determinations). Note that immediately after sublethal irradiation the spleen contains $2 \cdot 5 \mathrm{CFU}$ for every colony observed at 9 days in similar animals.

CFC and an increase by proliferation. At the time of the minimum there will be some foci in the spleen in which a CFC has already divided, thus there will be more than one CFC in some of the foci. These foci containing more than one CFC will form only one colony each and the number of CFC is thus higher than that of the colonies found 9 days later. Thus the observed recovery ratio (number of CFU recovered at the lowest point in the recovery curve/ number of colonies later found in the spleen) is higher than the ratio CFU/CFC which represents the true efficiency of the assay. In our study in Swiss mice (Lahiri \& van Putten, 1969a), the CFU recovery curve reaches a plateau of $9 \%$ during 1-2 days after injection. The true CFU/CFC ratio should therefore be lower than 0.09 . 
For a better evaluation of the CFU/CFC ratio we administered bone marrow cell suspensions to mice which had been irradiated 3 days earlier. The number of CFU recovered from the spleens of these mice increases exponentially almost immediately after injection (Fig. 3). Although some early loss of CFU may also occur in these animals, it seems that in these mice the number of colonies formed per spleen would be a closer estimate of the number

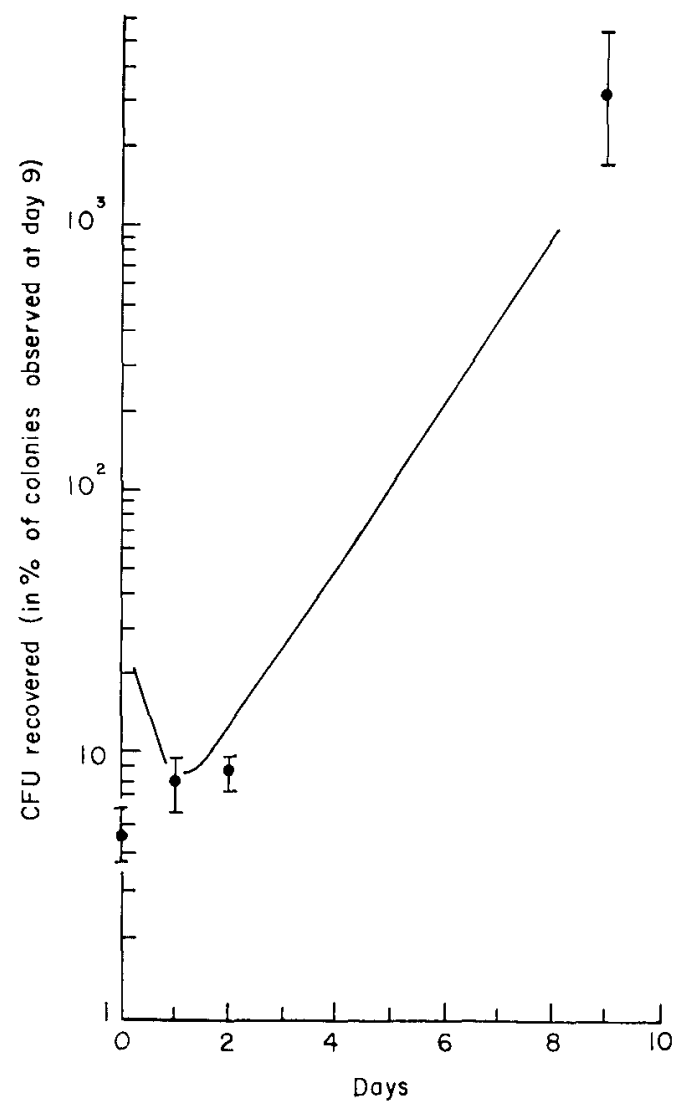

FIG. 3. Comparison of the growth of injected bone marrow CFU in the spleens of recipients irradiated $1-3 \mathrm{hr}$ and 3 days earlier. The curve refers to the recovery of CFU when the injection is given within $3 \mathrm{hr}$ after irradiation. (From Lahiri \& van Putten, 1969a.) The dots show the growth when there is a delay of 3 days between irradiation and injection (mean and SE of three or four separate determinations).

of colony forming cells present in the spleen early after injection. The CFU in the spleens were assayed in normal recipients and in Fig. 3 their numbers are presented. For every hundred colonies observed in the spleens of pre-irradiated recipients we can assume that nearly a hundred CFC were present at $2 \mathrm{hr}$ in these spleens. The fact that at $2 \mathrm{hr}$ these spleens were found to contain $5 \cdot 1 \pm 1 \cdot 3$ (mean \pm SE) CFU per 100 colonies observed later points to a CFU/CFC ratio of 0.05 .

It is clear that there are at least two processes involved in the low efficiency of CFU transplantation. The first is dependent on the cell fraction settling in the spleen, which is approached 
by the $2 \mathrm{hr}$ recovery fraction (Caper et al., 1970); and the second process is the early loss of CFU from these spleens in the next 1-2 days.

Vogel, Niewisch \& Matioli (1968) came to a similar conclusion on the basis of the distribution of CFU over colonies. Their data showed that 'according to the description of stem cell development by the stochastic model, one third of all stem cells which settle in the spleen of lethally irradiated mice is capable of forming macroscopically visible colonies' (Vogel et al., 1968). However, their estimate is based upon an assumed constant self-renewal probability and it cannot completely take into account the effect of the pronounced early loss of colony forming capacity.

Furthermore, they find an extremely low fraction of cells settling in the spleen of their irradiated mice as studied by comparison with intrasplenic injection (Matioli, Niewisch \& Vogel, 1968). This would lead to a calculated efficiency of $1-2 \%$ for potential colony forming cells in their assay system. Apart from these details their data also indicate that after settling in the spleen, all stem cells need not necessarily give rise to a colony and thus the overall efficiency of the assay is certainly below the 10-25\% figure derived from the $2 \mathrm{hr}$ cell distribution studies alone. However, the very low distribution factor which they observed contrasts markedly with that of other investigators, and it suggests that their system is different.

A more detailed analysis of stem cell kinetics in irradiated animals can only be performed if a better approximation of units and quantities is achieved and it seems necessary to replace the $2 \mathrm{hr}$ recovery fraction as the best estimate of the efficiency of the stem cell assay.

\section{ACKNOWLEDGMENTS}

The authors are grateful to Mr P. Lelieveld for technical collaboration. Thanks are also due to Miss L. K. J. Idsenga and Mrs L. v.d. Burg for skillful assistance.

\section{REFERENCES}

Caper, P., Smith, W.W., Fred, S.S. \& Wilson, S.M. (1970) Transplantability of labeled bone marrow cells into heavily irradiated recipient mice. (To be published).

Fred, S.S. \& SMITH, W.W. (1968) Induced changes in transplantability of hemopoietic colony forming cells (33015). Proc. Soc. exp. Biol. (N.Y.), 128, 364.

Hanks, G.H. \& Ainsworth, E.J. (1967) Repopulation of colony-forming units in mice. Nature (Lond.), $215,20$.

Kretchmar, A.L. \& Conover, W.R. (1969a) Early proliferation of transplanted spleen colony-forming cells. I. Proc. Soc. exp. Biol. (N.Y.), 131, 218.

Kretchmar, A.L. \& Conover, W.R. (1969b) Early proliferation of transplanted spleen colony-forming cells. II. Proc. Soc. exp. Biol. (N.Y.), 131, 703.

Kretchmar, A.L. \& Conover, W.R. (1969c) Colony-forming cells in the spleen. Transplantation, 8, 576.

Kubanek, B., Rencricca, N., Porcellini, A., Howard, D. \& Stohlman, F. (1969) The pattern of erythropoietic recovery in heavily irradiated mice receiving transplants of fetal liver. Proc. Soc. exp. Biol. (N.Y.), 131,831 .

LAHIRI, S.K. \& PUTTEN, L.M. van (1969a) Distribution and multiplication of colony forming units from bone marrow and spleen after injection in irradiated mice. Cell Tissue Kinet. 2, 21.

Lahiri, S.K. \& Putten, L.M. van (1969b) Modification of growth kinetics of colony-forming units in vivo. Radiation Induced Cancer, p. 107. I.A.E.A., Vienna.

Matioli, G., Vogel, H. \& Niewisch, H. (1968) The dilution factor of intravenously injected hemopoietic stem cells. J. cell. Physiol. 72, 229.

MCCulloch, E.A. \& Till, J.E. (1964) Proliferation of hemopoietic colony-forming cells transplanted into irradiated mice. Radiat. Res. 22, 383. 
Porteous, D.D. \& Lajtha, L.G. (1966) On stem-cell recovery after irradiation. Brit. J. Haemat. 12, 177.

Pozzi, L.V. \& SilinI, G. (1968) Kinetics of multiplication and differentiation of haemopoietic progenitor cells transplanted into irradiated mice. Effects of Radiation on Cellular Proliferation and Differentiation, p. 139. I.A.E.A., Vienna.

SCHOOLEY, J.C. (1966) The effect of erythropoietin on the growth and development of spleen colony-forming cells. J. cell. Physiol. 68, 249.

Siminovitch, L., McCulloch, E.A. \& Till, J.E. (1963) The distribution of colony-forming cells among spleen colonies. J. cell. comp. Physiol. 62, 327.

Smith, W.W., Wilson, S.M. \& Fred, S.S. (1968) Kinetics of stem cell depletion and proliferation: effects of vinblastine and vincristine in normal and irradiated mice. J. nat. Cancer Inst. 40, 847.

TiLl, J.E. \& MCCULLOCH, E.A. (1961) A direct measurement of the radiation sensitivity of normal mouse bone marrow cells. Radiat. Res. 14, 213.

Vogel, H., NiEwisch, H. \& Matioli, G. (1968) The self renewal probability of hemopoietic stem cells. $J$. cell. Physiol. 72, 221. 